\title{
Iodine recycling via 1,3-migration in iodoindoles under metal catalysis
}

\author{
Benito Alcaide, ${ }^{*}$ Pedro Almendros, ${ }^{b}{ }^{b}$ José M. Alonso, ${ }^{a}$ Sara Cembellín, ${ }^{a}$ Israel Fernández, ${ }^{c}$ Teresa \\ Martínez del Campo, ${ }^{a}$ and M. Rosario Torres ${ }^{d}$
}

\author{
Received (in $X X X, X X X) X$ th $X X X X X X X X X 20 X X$, Accepted Xth $X X X X X X X X X 20 X X$ \\ ${ }_{5}$ DOI: $10.1039 / b 000000 x$
}

3-Substituted (indol-2-yl)- $\alpha$-allenols show divergent patterns of reactivity under metal catalysis. An unprecedented intramolecular 1,3-iodine migration is described.

Despite that aryl halides are used in many metal-catalysed 10 synthetic developments, ${ }^{[1]}$ low atom economy is a disadvantage because the heteroatom is usually eliminated. A great challenge to be accomplished is the conversion of readily available aryl halides into halogenated products in which the heteroatom is not eliminated but reintegrated in the reaction product. ${ }^{[2]}$ Recently, 15 we have successfully reported metal-catalysed carbocyclizations of 3-unsubstituted (indol-2-yl)- $\alpha$-allenols for the direct preparation of the relevant carbazole nucleus. ${ }^{[3]}$ We envisioned that different behaviour of indole-tethered allenols might be achieved if the reactive C3-indole position was substituted with 20 an activating group. Herein, we report our findings starting from 3-halo- and 3-phenoxy-(indol-2-yl)- $\alpha$-allenols 1-4.

To explore the possibility of a 1,3-heteroatom migration, chloro- and bromoallenes $\mathbf{1}$ and $\mathbf{2}$ were initially chosen. Unfortunately, 2,5-dihydrofurans 5, formed through usual ${ }_{25}$ palladium-catalysed oxycyclization reaction, ${ }^{[4]}$ and dienes $\mathbf{6}$, formed via gold-catalysed rearrangement, were the only products formed (Scheme 1). The above experiments suggested that the halide recycling is troublesome.

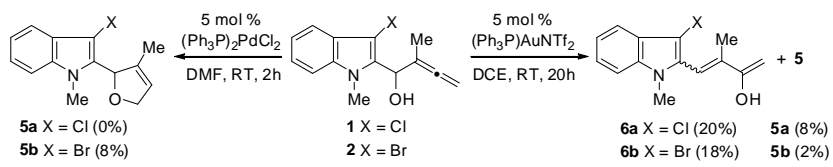

${ }_{30}$ Scheme 1 Metal-catalysed reactions of 3-chloro/bromo (indol-2-yl)- $\alpha$ allenols $\mathbf{1}$ and 2.

We thought that the use of a iodo-alkenyl rather than a $\mathrm{Cl}(\mathrm{Br})-$ species to initiate the allene functionalization could make the halogen recycling reaction possible. ${ }^{[2]}$ We first investigated the 35 reactions of allenols 3a-e bearing a C3-iodosubstituent at the indole nucleus under our previously optimized gold-catalysed conditions. Interestingly, a separable mixture of carbazoles 7a-e and iodocarbazoles 8a-e were obtained (Scheme 2). The iodocyclization of allenol 3a afforded the corresponding 340 iodocarbazole 8a in $69 \%$ yield and carbazole $7 \mathbf{a}$ in $7 \%$ yield. Diminished iodocarbazole/carbazole selectivity of ethyl- and phenyl-substituted reactans $\mathbf{3 b}$ and $\mathbf{3 c}$, were observed with respect to methyl-substituted allenes $\mathbf{3 a}$, $\mathbf{3 d}$ and $\mathbf{3 e}$. In addition of the expected carbazole $\mathbf{7 e}$ and iodocarbazole $\mathbf{8 e}$, 1-hydroxy-3-
45 iododihydrocarbazole 9e was also formed from chloroderivative 3e. It should be noted, that in our previous work on metalcatalyzed carbocyclizations 3-unsubstituted (indol-2-yl)- $\alpha$ allenols, we were not able to form iodocarbazoles $\mathbf{8}$ by trapping the postulated organometallic intermediate with halogenated 50 reagents. ${ }^{[3 a]}$ Considering the versatility of organic iodides in chemical transformations, iodinated carbazoles $\mathbf{8}$ are potentially interesting building blocks for further manipulation. ${ }^{[5]}$ The structure of 3-iodocarbazole 8d was unambiguously confirmed with the help of a X-ray diffraction analysis on suitable crystals 55 of this compound (Figure 1$){ }^{[6]}$

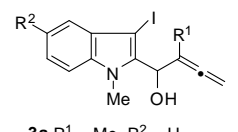

3a $R^{1}=M e, R^{2}=H$

$3 \mathbf{b} \mathrm{R}^{1}=\mathrm{Et}, \mathrm{R}^{2}=\mathrm{H}$

$3 c R^{1}=P h, R^{2}=H$

$3 d R^{1}=M e, R^{2}=O M e$

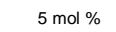
$\underset{\text { DCE, RT, 2-6h }}{\stackrel{\left(\mathrm{Ph}_{3} \mathrm{P}\right) \mathrm{AuNTf}_{2}}{\longrightarrow}}$ h

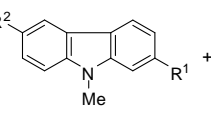

7 a $(7 \%)$ $7 \mathrm{~b}(38 \%)$ 7c $(33 \%)$ $7 d(10 \%)$

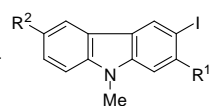

$8 \mathbf{a}(69 \%)$ $8 \mathbf{b}(41 \%)$ $8 \mathrm{c}(36 \%)$ 8d (46\%)

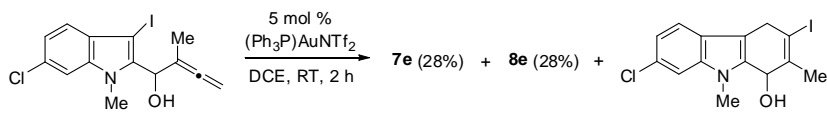
$\mathrm{Me} \mathrm{OH}$ 3e

9e (21\%)
Scheme 2 Synthesis of carbazoles 7, 3-iodocarbazoles 8, and 3iododihydrocarbazole 9e through carbocyclization/halogen recycling reactions of iodoallenols $\mathbf{3}$ under gold catalysis.

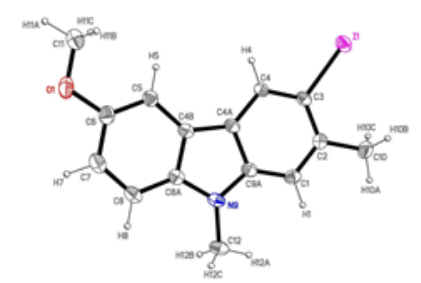

60

Figure 1 ORTEP drawing of 3-iodocarbazole 8d.

In an attempt to improve the iodocarbocyclization efficiency under related metal-catalysed conditions, we screened a different catalytic system such as $\mathrm{PdCl}_{2}\left(\mathrm{PPh}_{3}\right)_{2}$ on reacting with 3-iodo65 (indol-2-yl)-buta-2,3-dienol 3a. While the Pd-catalysed reaction proceeded with an optimal product distribution (100:0 ratio of the desired 1,3-iodine migration product to the non-iodinated carbazole), the isolated yield of 3-iodocarbazole 8a was poor (38\%). Therefore, we moved to a different catalytic system. 70 Finally, compound 8a was prepared in acceptable yield (61\%) via 
the reaction of $\mathbf{3 a}$ in the presence of a $\mathrm{Pd}-\mathrm{Cu}$ bimetallic system in DMF. Nicely, indoles $\mathbf{3 a}$, 3e, $\mathbf{3 f}$ and $\mathbf{3 h}$, bearing a methyl substituent on the allene moiety, furnished exclusively 3iodocarbazoles $\mathbf{8 a}, \mathbf{8 e}, \mathbf{8 f}$ and $\mathbf{8 h}$ (Scheme 3). Unfortunately, 5 attempts to use phenyl-substituted substrates $\mathbf{3 c}$ and $\mathbf{3 g}$ proved to be unsuccessful for the construction of the corresponding iodocarbazoles, possibly because of both unfavourable steric factors as well as a direct interaction of the $\pi$-aromatic system with the metal center from the catalyst. In addition to atom 10 economy and bond-forming efficiency, the above metal-catalysed cases in Scheme 2 and Scheme 3, may be considered as examples of the rare recycling of halogen groups via 1,3-halogen migration. ${ }^{[7]}$
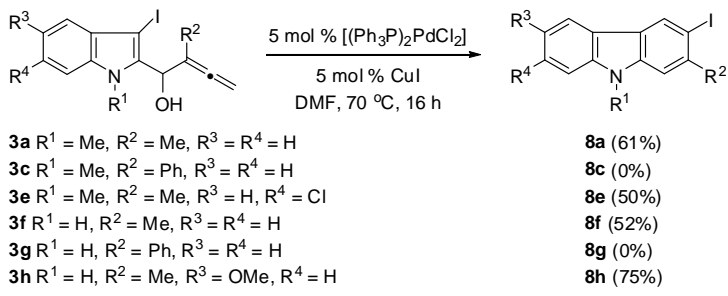

${ }_{15}$ Scheme 3 Synthesis of 3-iodocarbazoles 8 through carbocyclization/halogen recycling reactions of iodoallenols 3 under palladium catalysis.

Next, the annulations of 3-phenoxy-(indol-2-yl)- $\alpha$-allenols 4 were examined (Scheme 4). To test the reactivity of allenes $\mathbf{4}$, we 20 started the initial investigation on the gold-catalysed reaction of allene 4a under otherwise identical reaction conditions used for its iodocounterpart 3a. Interestingly, it was found that substrate 4a was exclusively transformed into the 1-hydroxycarbazole 10a (Scheme 4). This interesting transformation can be explained 25 through a gold-catalysed allenic carbocyclization with concomitant hydrodephenoxylation (see below). Thus, it was encountered that the synthesis of structurally interesting 1oxygenated carbazoles, could be controlled by the C3-substituent on the indole ring in allenes of type 1-4. Next, 3-phenoxy-(indol30 2-yl) allenes $\mathbf{4 b}$ and $\mathbf{4 c}$ were examined in this reaction (Scheme 4). Allene $\mathbf{4 b}$ was successfully converted to 1-methoxycarbazole 10b in fair yield in the presence of the Gagosz' catalyst. ${ }^{[8]}$ On the contrary, phenyl-substituted allene $\mathbf{4 c}$ could not lead to the formation of the corresponding 1-hydroxycarbazole, affording 35 instead the 2,5-dihydrofuran 5c. Hence, the hydroxy group in phenyl-substituted 3-phenoxy-(indol-2-yl)- $\alpha$-allenol $\quad 4 \mathbf{c}$ exclusively suffers 5-endo oxycyclization reaction, instead of 6endo carbocyclization.

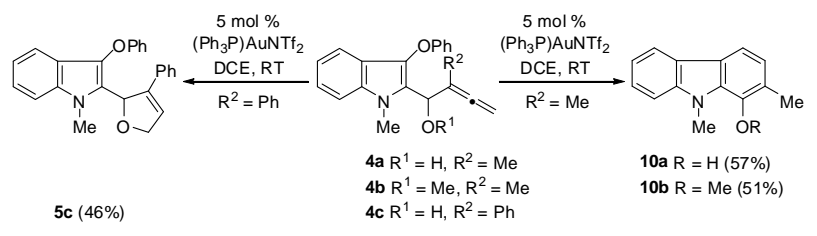

40 Scheme 4 Synthesis of 1-oxygenated carbazoles $\mathbf{1 0}$ through carbocyclization/hydrodephenoxylation reaction of phenoxyallenols 4 under gold catalysis.

A possible pathway ${ }^{[9]}$ for the gold-catalysed generation of 1oxygenated carbazoles $\mathbf{1 0}$ is outlined in Scheme 5. Initially, the
${ }_{45}$ formation of a complex 4 -Au(L) through coordination of the gold salt to the distal allenic double bond may be involved. Species 4$\mathrm{Au}(\mathrm{L})$ suffers an intramolecular chemo- and regioselective 6endo-trig carbocyclization reaction to produce the auratetrahydrocarbazole 11. This nucleophilic attack from the C350 indole site occurs as a result of the stability of the intermediate iminium type cation 11. Next, a phenol elimination ${ }^{[10]}$ step occurs in tricycle 11 through $\mathrm{C} 3-\mathrm{OPh}$ bond cleavage to generate the dihydrocarbazolium 12. Aromatization by loss of proton generates neutral species 13, which followed by protonolysis of 55 the carbon-gold bond afforded 1-oxygenated carbazoles $\mathbf{1 0}$ with concurrent regeneration of the gold catalyst (Scheme 5).

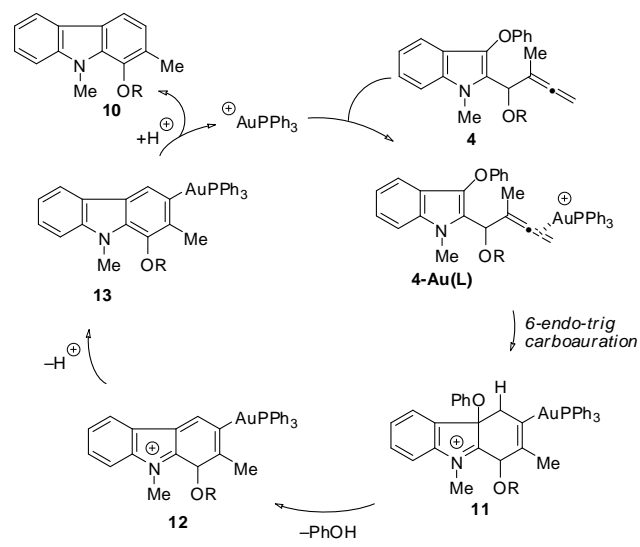

Scheme 5 Mechanistic explanation for the Au(I)-catalyzed synthesis of 1oxygenated carbazoles $\mathbf{1 0}$ from phenoxyallenols 4 .

60 Density functional theory (DFT) calculations have been carried out at the PCM-M06/def2-SVP//B3LYP/def2-SVP level ${ }^{[11]}$ to gain more insight into the reaction mechanism of the above discussed transition metal-catalysed carbocyclization/halogen recycling reactions of iodoallenols 3 . Thus, the corresponding 65 computed reaction profile of the reaction of allenol 3a and the model catalyst $\mathrm{AuPMe}_{3}{ }^{+}$is shown in Figure 2, which gathers the respective free energies, $\Delta \mathrm{G}_{298}$, in dichloroethane solution.

The process begins with the exergonic coordination of the catalyst to the distal allenic double bond of $\mathbf{3 a}$ to form 70 intermediate INT1 $\left(\Delta \mathrm{G}_{\mathrm{R}, 298}=-11.9 \mathrm{kcal} / \mathrm{mol}\right)$. Then, the nucleophilic attack of the C3-indole position onto the gold(I)activated double-bond delivers auratetrahydrocarbazole INT2. This carbocyclization reaction occurs through transition state TS1 with an activation barrier of $\Delta \mathrm{G}_{298}^{\neq}=14.0 \mathrm{kcal} / \mathrm{mol}$ in an 75 exergonic transformation $\left(\Delta \mathrm{G}_{\mathrm{R}, 298}=-6.6 \mathrm{kcal} / \mathrm{mol}\right)$, which is compatible with a process at room temperature. Alternatively, it has been recently suggested that species related to INT2 may be formed from spiranic species INT2' through a 1,2-migration reaction. ${ }^{[12]}$ However, our calculations indicate that the initial 80 formation of INT2' via TS1', a saddle point associated with the C2-indole nucleophilic attack, is kinetically and thermodynamically less favoured than the process involving TS1, which makes the alternative pathway non-competitive. The origins of this behaviour are found in the well-known activation 85 of the C3-carbon atom by the nitrogen atom of the indole. ${ }^{[13]}$ Once INT2 is formed, it is transformed into the iodonium species INT3 through TS2 (activation barrier of $\Delta \mathrm{G}^{\neq}{ }_{298}=16.8 \mathrm{kcal} / \mathrm{mol}$ ) in an exergonic process $\left(\Delta \mathrm{G}_{\mathrm{R}, 298}=-2.7 \mathrm{kcal} / \mathrm{mol}\right)$. As shown in Figure 2, TS2 is associated with the 1,3-migration of the iodine 
atom to the endocyclic double bond of the adjacent six-membered ring. This step resembles that for typical electrophilic halogen addition to alkenes. Indeed, the computed positive NBO-charge at iodine atom in INT3 $(q=+0.35$ e) clearly confirms the cyclic5 iodonium cation nature of this species. Therefore, this step can be viewed as an unprecedented intramolecular iodine cation addition to a metal-activated double bond. The next step of the transformation involves the liberation of the metal catalyst through formation of the corresponding iododihydrocarbazoles $\mathbf{9}$

10 from INT4. Subsequent aromatization by dehydration would produce the observed 3-iodocarbazoles 8. Although the isolation of tricycle $\mathbf{9 e}$ from the reaction of $\mathbf{3 e}$ outlined in Scheme 2 was fortuitous, the result argues in favour of the suggested reaction mechanism, because an observable intermediate of type 9 was 15 formed.

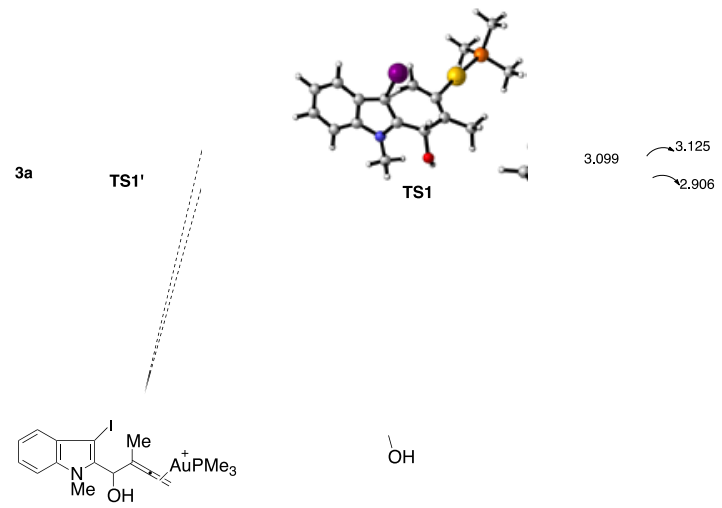

Figure 2 Computed reaction profile (PCM(dichloroethane)-M06/def2SVP// B3LYP/def2-SVP level) for the reaction between 3a and $\mathrm{AuPMe}_{3}{ }^{+}$. Relative free energies are given in $\mathrm{kcal} / \mathrm{mol}$ and bond distances in the 20 transition states in angstroms.

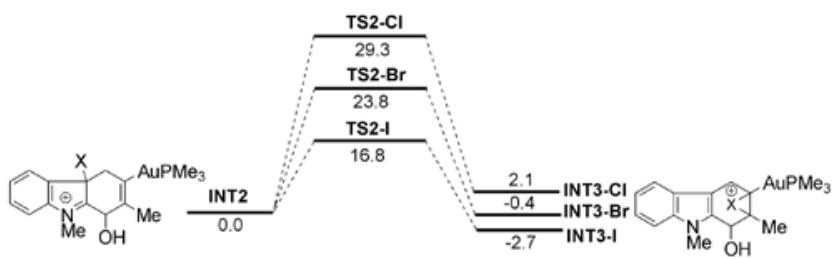

Figure 3 Comparison of the migratory aptitude of halogen atoms in the proposed 1,3-shift. Relative free energies are given in $\mathrm{kcal} / \mathrm{mol}$. All data have been computed at the PCM(dichloroethane)-M06/def2-SVP// 25 B3LYP/def2-SVP levels.

Finally, we have also investigated why chlorine or bromine substituted allenols $\mathbf{1}$ and $\mathbf{2}$ do not undergo a similar 1,3migration to that found for iodoallenols $\mathbf{3}$. As clearly seen in Figure 3, the computed activation barriers associated with the 30 1,3-halogen shifts involving chlorine and bromine atoms are much higher than the barrier associated with the migration of iodine $\left(\Delta \mathrm{G}_{298}^{f}=29.3\right.$ and $23.8 \mathrm{kcal} / \mathrm{mol}$ for $\mathrm{Cl}$ and $\mathrm{Br}$, respectively). Therefore, our calculations suggest that the migratory aptitude of halogen atoms in this transition metal35 mediated process follows the order $\mathrm{I}>\mathrm{Br}>\mathrm{Cl}$, which is in nice agreement with the experimental findings. ${ }^{[14]}$
In conclusion, in salient contrast to the reaction of 3-phenoxy(indol-2-yl) allenes, which were transformed into 1-oxygenated carbazoles, 3-iodo-(indol-2-yl) allenes afforded 3-iodocarbazoles 40 through rare recycling of halogen groups via 1,3-halogen migration. Besides, a computational study suggested the intermediacy of an iodonium cation species formed through an unprecedented intramolecular iodine cation addition to a metalactivated double bond.

45 Support for this work by the MINECO [Projects CTQ201233664-C02-01, CTQ2012-33664-C02-02, CTQ2010-20714-C0201, and Consolider-Ingenio 2010 (CSD2007-00006)], and CAM (Projects S2009/PPQ-1752 and S2009/PPQ-1634) are gratefully acknowledged. S. C. thanks MEC for a predoctoral grant. J. M. 50 A. thanks Comunidad Autónoma de Madrid and Fondo Social Europeo for a postdoctoral contract.

\section{Notes and references}

${ }^{a}$ Grupo de Lactamas y Heterociclos Bioactivos, Departamento de Química Orgánica, Unidad Asociada al CSIC, Facultad de Química, 55 Universidad Complutense de Madrid, 28040-Madrid, Spain. Fax: +34 91-3944103; E-mail: alcaideb@quim.ucm.es

${ }^{b}$ Instituto de Química Orgánica General, IQOG, CSIC, Juan de la Cierva 3, 28006-Madrid, Spain. Fax: +34 91-5644853; E-mail:

Palmendros@iqog.csic.es

$60{ }^{c}$ Departamento de Química Orgánica, Facultad de Química, Universidad Complutense de Madrid, 28040-Madrid, Spain

${ }^{d}$ CAI Difracción de Rayos X, Facultad de Química, Universidad

Complutense de Madrid, 28040-Madrid, Spain

$\dagger$ Electronic Supplementary Information (ESI) available: Experimental

65 procedures, characterization data of new compounds, computational details, and copies of NMR spectra. See DOI: 10.1039/b000000x/

1 Chem. Soc. Rev., 2011, 40, themed issue 10, Cross coupling reactions in organic synthesis.

2 For an overview, see: J. M. Schomaker and R. D. Grigg, Synlett, $70 \quad 2013,401$

3 (a) B. Alcaide, P. Almendros, J. M. Alonso, M. T. Quirós and P. Gadziński, Adv. Synth. Catal., 2011, 353, 1871; (b) B. Alcaide, P. Almendros, J. M. Alonso and I. Fernández, Chem. Commun., 2012, 48, 6604 .

754 S. Ma, Chem. Rev., 2005, 105, 2829.

5 (a) J. Li and A. C. Grimsdale, Chem. Soc. Rev., 2010, 39, 2399; (b) A. W. Schmidt, K. R. Reddy and H.-J. Knölker, Chem. Rev., 2012, 112, 3193.

6 CCDC-926119 contains the supplementary crystallographic data for 80 this paper (www.ccdc.cam.ac.uk/data_request/cif).

7 (a) R. D. Grigg, R Van Hoveln and J. M. Schomaker, J. Am. Chem. Soc., 2012, 134, 16131; (b) S. G. Newman and M. Lautens, J. Am. Chem. Soc., 2011, 133, 1778; (c) P. Nösel, T. Lauterbach, M Rudolph, F. Rominger and A. S. K. Hashmi, Chem. Eur. J., 2013, 19 858634.

8 N. Mézailles, L. Ricard and F. Gagosz, Org. Lett. 2005, 7, 4133.

9 A. S. K. Hashmi, Angew. Chem. Int. Ed. 2010, 49, 5232.

10 (a) A. S. K. Hashmi, W. Yang and F. Rominger, Angew. Chem. Int. Ed. 2011, 50, 5762; (b) A. S. K. Hashmi and M. Wölfle, 90 Tetrahedron, 2009, 65, 9021.

11 See Computational Details in the ESI.

12 B. Cheng, G. Huang, L. Xu and Y. Xia, Org. Biomol. Chem., 2012, 10, 4417.

13 (a) J. Barluenga, E. Tudela, A. Ballesteros and M. Tomás, J. Am. $95 \quad$ Chem. Soc., 2009, 131, 2096; (b) T. Cao, J. Deitch, E. C. Linton, M. C. Kozlowski, Angew. Chem. Int. Ed., 2012, 51, 2448.

14 A similar trend has been observed in 1,2-dyotropic reactions. See: (a) I. Fernández, F. M. Bickelhaupt and F. P. Cossío, Chem. Eur. J., 2012, 18, 12395. For a recent review on dyotropic reactions, see: (b)

100 I. Fernández, F. P. Cossío and M. A. Sierra, Chem. Rev., 2009, 109, 6687. 
Autores: Alcaide, B.; Almendros, P.; Alonso, J. M.; Cembellín, S.; Fernández, I.; Martínez del

Campo, T.; Torres, M. R.

${ }_{5}$ Título: Iodine Recycling via 1,3-Migration in

Iodoindoles under Metal Catalysis

Revista: Chem. Commun. 2013, 49, 7779-7781 